University of Wollongong

Research Online

Faculty of Business - Papers (Archive)

Faculty of Business and Law

$1-1-2014$

'Branding' explained: defining and measuring brand awareness and brand attitude

John R. Rossiter

University of Wollongong, jrossite@uow.edu.au

Follow this and additional works at: https://ro.uow.edu.au/buspapers

Part of the Business Commons

Research Online is the open access institutional repository for the University of Wollongong. For further information contact the UOW Library: research-pubs@uow.edu.au 


\title{
'Branding' explained: defining and measuring brand awareness and brand attitude
}

\begin{abstract}
Writing in the very first issue of this journal, the present author proposed a comprehensive model of 'branding', a managerial process that requires the marketer to establish, in the consumer's mind, two essential communication effects: brand awareness and then brand attitude. In the present article, he expands this model from two to now three types of brand awareness (brand recognition, category-cued brand-name recall and brand recall-boosted recognition) and from three to now five levels of brand attitude (reject, unaware, acceptable if on special, one of my several preferred brands and my single preferred brand). Also, he shows how to most efficiently measure these two necessary components of branding.
\end{abstract}

\section{Keywords}

attitude, branding, awareness, brand, measuring, defining, explained

Disciplines

Business

\section{Publication Details}

Rossiter, J. R. (2014). 'Branding' explained: defining and measuring brand awareness and brand attitude. Journal of Brand Management, 21 (7/8), 533-540. 
Original Article

"Branding" explained: Defining and measuring

brand awareness and brand attitude

\author{
John R. Rossiter
}

is Research Professor of Marketing at the University of Wollongong in Australia. His interests include marketing knowledge, marketing measurement, consumer behavior, and advertising and promotion management. He is author or co-author of nine books in these fields and has published more than 80 articles in leading journals.

ABSTRACT Rossiter (1993) writing in the very first issue of this Journal proposed a comprehensive model of "branding," a managerial process that requires the marketer to establish, in the consumer's mind, two essential communication effects: brand awareness and then brand attitude. In the present article he expands this model from two to now three types of brand awareness (brand recognition, category-cued brand-name recall, and brand recall-boosted recognition) and from three to now five levels of brand attitude (reject, unaware, acceptable if on special, one of my several preferred brands, and my single preferred brand). Also, he shows how to most efficiently measure these two necessary components of branding.

Keywords: branding as positioning; brand awareness types; brand attitude levels; efficient measures 
"Branding" is a term much bandied about that has escaped proper definition because everyone, like the proverbial blind men in the presence of the elephant, thinks they know what it means. David Aaker (2014), for instance, touted by master textbook writer Philip Kotler as being the "Father of Modern Branding," in his new book Aaker on Branding nowhere defines the term "branding" and the word is not even listed in the book's index. Aaker does, however, define "brand," describing it as "Far more than a name and logo, it is an organization's promise to a customer to deliver what a brand stands for...in terms of functional benefits but also emotional, self-expressive, and social benefits" (Aaker, 2014, p. 1). Seen from the perspective of the present article, the first part of Aaker's definition refers vaguely to brand awareness ("a name and logo") and the last part refers obscurely to brand attitude (which is what is presumed to result from the "benefits"). When studying branding, however, academics such as those publishing recently in this Journal ignore brand awareness altogether. Taute, Peterson, and Sierra (2014), for instance, define branding as involving "both a cognitive and an emotive bond" (p. 23) but these "bonds," as will be demonstrated in the present article, relate only to brand attitude.

Rossiter and Percy's first edition of Advertising and Promotion Management (1987) was the first publication to properly define what marketing practitioners later called "branding." Rossiter and Percy defined branding as the achievement, in the prospective buyer's mind, of a favorable brand attitude given that the prospect had already acquired brand awareness. They defined these two brand communication effects as jointly necessary - their reasoning was that it is no use for the brand manager to create a favorable attitude if potential buyers can't recall the brand prior to purchase or recognize it at the point of purchase. The omission of brand awareness is the big mistake made by practitioners and by academics when they talk about, write about, and try to measure "branding." 
Rossiter and Percy (1997) in the second edition of their advertising and promotion management textbook showed how brand awareness and brand attitude combine in their "macro" model of brand positioning. This model is now (Rossiter, Percy, and Slowikowski, forthcoming) called the C-U-B Branding Model of Positioning and is depicted in Figure 1. The C-U-B model of brand positioning - branding - asks three basic questions about the brand: What is it [category]? Who is it for [user]? What does it offer [benefit/s]? As the diagram shows, brand awareness, on the left, is the brand-category connection; brand attitude, at the bottom of the diagram, is the result of either a "transformational" brand-user connection or an "informational" brand-benefit connection.

Figure 1 about here

The present article conceptually expands on the definition and measurement of brand awareness and brand attitude - the essential components of branding. Brand awareness is shown to consist of three distinct types; these types are based on how the brand has to be identified by the buyer for purchase consideration. Brand attitude, the second component of branding, is shown to differ for the same brand depending on the buyer's buying motive, and here the exposition takes a necessary detour into Rossiter and Percy's $(1987,1997)$ emotionshift theory, an important practical theory overlooked by all marketing academics and most practitioners. Finally, efficient measures are provided for the three types of brand awareness and for overall brand attitude. 


\section{BRAND AWARENESS}

Brand awareness is defined as the buyer's ability to identify the brand in sufficient detail to make a purchase (Rossiter and Percy, 1987, 1997). Brand awareness is a necessary precursor to brand attitude.

The precursor principle can be demonstrated with the straightforward example of ordering an imported beer to impress your friends at a trendy restaurant. Suppose that when brand attitudes are measured in isolation, which is the common practice among market researchers, that you have an equally favorable attitude toward two imported beer brands, Heineken and Beck's (let's say you would rate them both 9 out of 10 , or .9 on a 0 to 1.0 probability scale). But suppose that you are much more likely to recall Heineken when asked by drink waiters in upmarket situations; let's put your probability of recalling Heineken first, since you only want to order one brand at a time, at .8, and your probability of recalling Beck's first at .2. Remember, you are attitudinally indifferent between the two beers - you prefer them equally. But over many such occasions, you will choose Heineken much more often because the probability of choosing Heineken on any one occasion, assuming that you mentally check your attitude toward each brand you recall, is $.8 \times .9=.72$, whereas your choice probability for Beck's is just $.2 \times .9=.18$. This drastic difference in personal "market shares" would be missed by the researcher if brand awareness were not measured prior to brand attitude.

\section{Correct type of brand awareness}

Also missed by all researchers is the necessity of measuring the correct type of brand awareness. The choice-appropriate type of brand awareness can be obtained from either the researcher's common knowledge of consumers and of the category or, if the researcher is unsure, from conducting a dozen or so (and 20 is usually enough as long as you have taken a 
reasonably representative sample of category buyers) one-on-one qualitative interviews in which you ask the consumer to mentally "walk through" and "talk through" his or her most recent purchase in the target situation - ordering beer in a high-end restaurant in the above example. Rossiter and Percy (1997) call this the construction of a behavioral sequence model.

Table 1 about here

Now look at Table 1. You will see that there are three distinct types of brand awareness, depending on the majority choice process identified from the behavioral sequence model, and that they are measured differently. The three different "paths" to brand awareness are depicted in Figure 2.

Figure 2 about here

\section{Brand recognition}

When the brand choice is made at the point of purchase - such as in a real store or an online catalog-like store - brand recognition is the type of brand awareness the manager needs to aim for. Think now about what the prospective buyer actually has to recognize. It might be the spoken brand name (for example, if you were to ask the waiter in the restaurant "What imported beers do you have?"). It might be visually the brand logo (for example, looking for the H\&M store logo in a shopping mall). Or it might be, also visually, the stylized brand name (for example, SONY if you are shopping for a new TV set). 
This means that the brand stimulus in the measure of brand recognition must be represented iconically - that is, just as the consumer would hear it or see it. Also, the brand recognition measure should be answered as "Yes," "No," or "Not sure" with only the "Yesses" counted as correct recognition.

\section{Category-cued brand-name recall}

When the brands to be considered must be recalled prior to the point of purchase, categorycued brand-name recall is the only relevant type of brand awareness. Examples of situations in which category-cued brand-name recall is necessary would be deciding before you leave home which department stores or boutiques you will visit to buy a new cocktail dress or tuxedo; or, for a business manager, nominating a preferred courier for an overseas delivery, such as Fedex, DHL, or some other recalled brand.

Notice that this is not "free recall" but name recall in response to the product or service category as the initiating cue. The measure must therefore incorporate this category cue in the measure (and in consumer language, not technical language). Secondly, the researcher has to decide beforehand what constitutes "adequate-for-choice" name recall (example: Would "Apple iPhone" suffice or must it be "Apple iPhone 6" or "Apple iPhone 6 Plus" - the latest Apple smartphone models at the time of writing). Lastly, the researcher also has to decide the cutoff for name recall. The cutoff can be determined quite accurately from the behavioral sequence model interviews. In time-pressed choice situations it is usually one brand; low-risk or "low involvement" choices, two; and "high involvement" about four, with reverse weighting $(4,3,2,1)$ by order of recall since earlier-recalled brands are more likely to be chosen.

\section{Brand recall-boosted recognition}


Because of, these days, the massive size of shopping centers and the emergence of megastores within these centers, a third type of brand awareness is needed for brands (branded items) sold in these giant distributors' displays. This Rossiter and Percy (1997) call brand recall-boosted recognition, in which the prospective buyer first has to recall the brand name or a color visual image of the brand's pack or logo, then has to be able to recognize it at the point of purchase.

The measure of brand recall-boosted recognition is thus a two-stage measure as described in the table. Category-cued brand-name recall is measured first, followed by the measure of brand recognition - in which only those recognized brands that are recalled are given a positive score for brand awareness.

\section{BRAND ATTITUDE}

Once the appropriate type of brand awareness has been achieved, brand choice then proceeds on the basis of brand attitude among the personally "aware of" brands.

Rossiter and Percy $(1987,1997)$ define brand attitude in a particular way. Brand attitude is defined as the buyer's evaluation of the brand with respect to its expected capacity to deliver on a currently relevant buying motive. This motive-anchored definition means that the prospective buyer can hold different overall attitudes toward the same brand depending on his or her main reason for buying it on a particular purchase occasion (the behavioral sequence model again). Examples of these differential attitudes toward the same brand are common in everyday life but totally neglected in the marketing literature. Some examples:

- Beck's beer - evaluation as a "prestige" beer vs. evaluation as a privately consumed "at home" beer where its higher price may be prohibitive

- Sears stores - evaluation as a place to buy "home handyperson" clothes vs. "white-collar officewear" clothes 
- Apple computers - evaluation if your usage need is for "graphic design" vs. "advanced computation" (although this difference may be somewhat historical and stereotyped)

A brief rundown of the two very different types of buying motive is given in Table 2 (and the motivational distinction is unique to the Rossiter-Percy approach). There it can be seen that there are five main "negatively reinforcing," product-focused, problem-solving motives and five main "positively reinforcing," user-focused, experience-enhancing motives. These correspond with benefit attitudinal positioning and user attitudinal positioning as depicted in Figure 1 earlier.

Table 2 about here

\section{Brand attitude formation, increase, and change}

Rossiter and Percy (1997) propose the following dynamic model for accomplishing formation, increase, or change in overall brand attitude:

$$
\text { BATT }_{b}=\sum_{i=1}^{n}\left(B_{b i} E_{i}\right)+\underset{e=1}{m} E_{b e}
$$

where

$$
\begin{aligned}
& \text { BATT }_{\mathrm{b}}=\begin{array}{l}
\text { overall attitude toward brand } \mathrm{b} \text { (attitude for serving a particular } \\
\text { buying motive) }
\end{array} \\
& \mathrm{B}_{\mathrm{bi}}=\begin{array}{l}
\text { benefit belief } \mathrm{B} \text { about brand b's delivery on benefit } \mathrm{i}(1 \ldots \mathrm{i} \ldots \mathrm{n} \\
\text { benefits) }
\end{array} \\
& \mathrm{E}_{\mathrm{i}}=\text { evaluation or importance of benefit } \mathrm{i} \\
& \mathrm{E}_{\mathrm{be}} \quad=\text { freestanding emotions connected to brand } \mathrm{b} \text { (1...e...m emotions) }
\end{aligned}
$$

The brand attitude model may be easier to understand graphically as in Figure 3. 
Figure 3 about here

The most frequent situation facing marketers is to accomplish a brand attitude increase - most often to persuade FBSs (favorable brand-switchers) who rate our brand as "one of my preferred brands" to move up to become BLs (brand loyals) who will then regard our brand as "my single preferred brand." (See the measure of overall brand attitude in the last panel of Table 2.) Alternative strategies for increasing the buyer's brand attitude, BATT above, are as follows:

1. Increase the brand's perceived delivery on an important benefit $\left(\mathrm{B}_{\mathrm{bi}}\right)$.

2. Increase the evaluation or importance of a benefit on which the brand delivers uniquely $\left(\mathrm{E}_{\mathrm{i}}\right)$.

3. Add a new benefit which is positively evaluated or high importance and on which the brand can be perceived as delivering uniquely (new $B_{b i} E_{i}$ with now $n+1$ benefits).

4. Add a strong positive freestanding emotion $\left(\mathrm{E}_{\mathrm{be}}\right)$.

5. Alter the choice rule to favor our brand $(\Sigma)$.

Strategy \#1, increasing the brand's perceived delivery on an important benefit (increase $\mathrm{B}_{\mathrm{bi}}$ ), is nearly always the only strategy addressed in the marketing literature. Taute et al.'s (2014) research on the appeal of smartphones and their operating systems, for instance, presumes this brand attitude strategy. The current battle between Apple's iPhone and Samsung's Galaxy, for example, is being fought principally over delivery of the benefit of ever-larger screen size, turning these phones into "phablets."

But the other attitude-increase strategies are also worth exploring. ConAgra's Healthy Choice frozen dinners in the U.S., for example, dramatized the importance of the 
"heart-healthy" benefit - ConAgra's CEO had suffered a heart attack - and its low fat, low cholesterol, low sodium frozen entree line rocketed to market leadership over Stouffer's Lean Cuisine (strategy \#2). Crest toothpaste became market leader in the U.S. by adding a thennew and radically important cavity-reducing benefit, sodium fluoride (strategy \#3). "Experiential" brands - transformational in Rossiter-Percy terms - are often sold by finding a strong positive freestanding emotion to connect to the brand, which has nothing at all to do with benefits; examples are McDonald's "I'm lovin' it" and Smirnoff Vodka's "Pure thrills" campaigns (strategy \#4). The most difficult strategy is altering the buyer's choice rule (strategy \#5); rarely attempted other than by governments, "Five-a-Day" servings of vegetables and fruit and "Ask for the Generic" for prescription medicines or over-the-counter drugs are examples.

\section{Emotion-shift theory}

As mentioned, and as described in Table 2, Rossiter and Percy's definition of brand attitude presumes that the attitude is based on a specific buyer motive active at the time. Motives, in turn, are activated by emotions - emotional states - both felt and anticipated. Locked within the $\Sigma\left(\mathrm{B}_{\mathrm{bi}} \mathrm{E}_{\mathrm{i}}\right)$ term of the BATT $\mathrm{b}$ model given earlier, not in the freestanding emotions $\Sigma \mathrm{E}_{\mathrm{be}}$ term, is Rossiter and Percy's $(1987,1997)$ emotion-shift theory. This is a facet of brand attitude overlooked by all academic advertising researchers - but well known, at least implicitly, to advertising copywriters. To motivate buyers, you have to achieve an emotion shift.

Look again at Table 2. The informational motives each require a shift from a negative emotion (the "problem") to a neutral or mildly positive emotion (the "solution" delivered by the brand). The transformational motives each require a shift from a neutral or mildly negative emotion to a very positive emotion (the "experience enhancer"). Examples 
of the specific pre-to-post emotions dynamically inherent in each motive are given in the table.

\section{Brand attitude measurement}

Focusing now on the measurement of overall attitude toward the brand - BATT $\mathrm{b}$ in the brand attitude model - the most efficient and managerially meaningful measure is provided in the bottom panel of Table 2. The origin of this 5-level measure is uncertain; Rossiter picked up on it in Australia from his colleague Dr. Max Sutherland who invented the MarketMind (now TNS) system of continuous brand tracking, though Max thinks it might have come from the Australian division of Colgate or one of the leading packaged goods companies.

This single-item measure asks the respondent to place each of the surveyed brands into one of five clearly understandable categories - single preferred, one of several preferred, acceptable only on promotion, not acceptable, and don't know this brand. Note that this single item efficiently measures, albeit crudely, brand awareness - assumable if the respondent gives any answer other than "don’t know" - and, adequately finely, brand attitude.

Two things to pay attention to when using this measure are, firstly, to precede the measure by the situational buying motive (for example, the social-approval motive implied in the measure's prestatement "If you were buying one of these wines as a gift for your Dad...") and, secondly, to not score the answers like a rating scale $(5,4,3,2,1$ is typical). For the quantitatively obsessed researcher, scoring weights are suggested in the table but the realworld manager is advised to simply count, for our brand, the proportion of the survey respondents who "shift boxes" from before to after the brand's marketing campaign. Obviously a large proportion shifting to the top box or at least to the second box is desirable, but large numbers shifting downward is a similarly informative if much more worrying result. 
Most concerning - and the theme of this article - would be a large number in the

"don't know this brand" box, which means failure to achieve brand awareness and therefore a failure of branding.

\section{REFERENCES}

Aaker, D. (2014). Aaker on Branding. New York: Morgan James.

Rossiter, J.R. (1993). Brand awareness and acceptance: A seven-set classification for managers. Journal of Brand Management 1(1): 33-40.

Rossiter, J.R. and Percy, L. (1987). Advertising and Promotion Management. New York: McGraw-Hill.

Rossiter, J.R. and Percy, L. (1997). Advertising Communications \& Promotion Management. New York: McGraw-Hill.

Rossiter, J.R., Percy, L., and Slowikowski, S. (forthcoming). Managing Advertising and Promotion.

Taute, H.A., Peterson, J., and Sierra, J.J. (2014). Perceived needs and emotional responses to brands: A dual-process view. Journal of Brand Management 21(1): 23-42. 
Figure 1: C-U-B branding model of positioning. The roles of the core communication effects, brand awareness and brand attitude, are also shown.

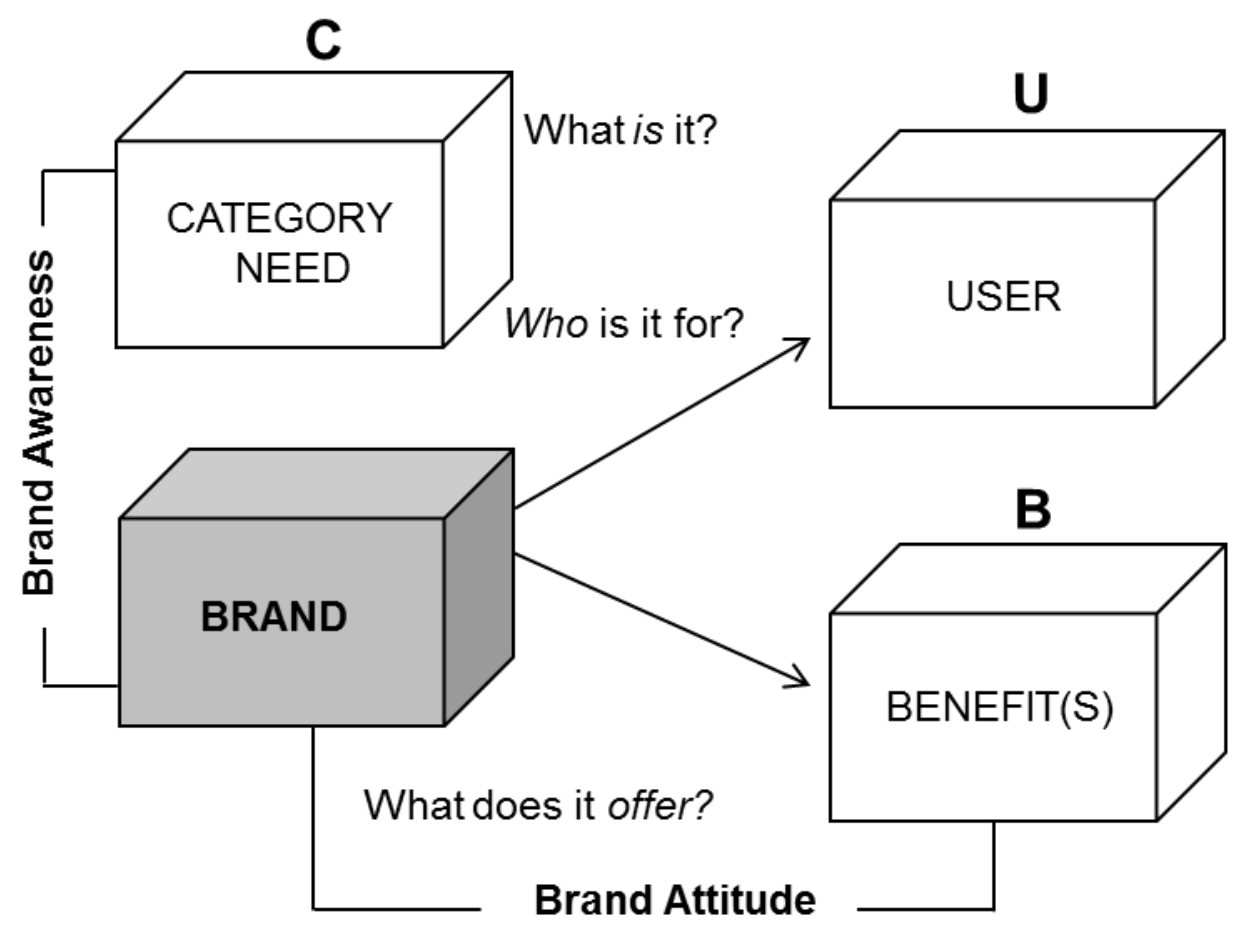


Figure 2: Schematic representation of the relationship of brand awareness to category need - showing brand recognition (Path 1), category-cued brand-name recall (Path 2), and brand recall-boosted recognition (Path 3).

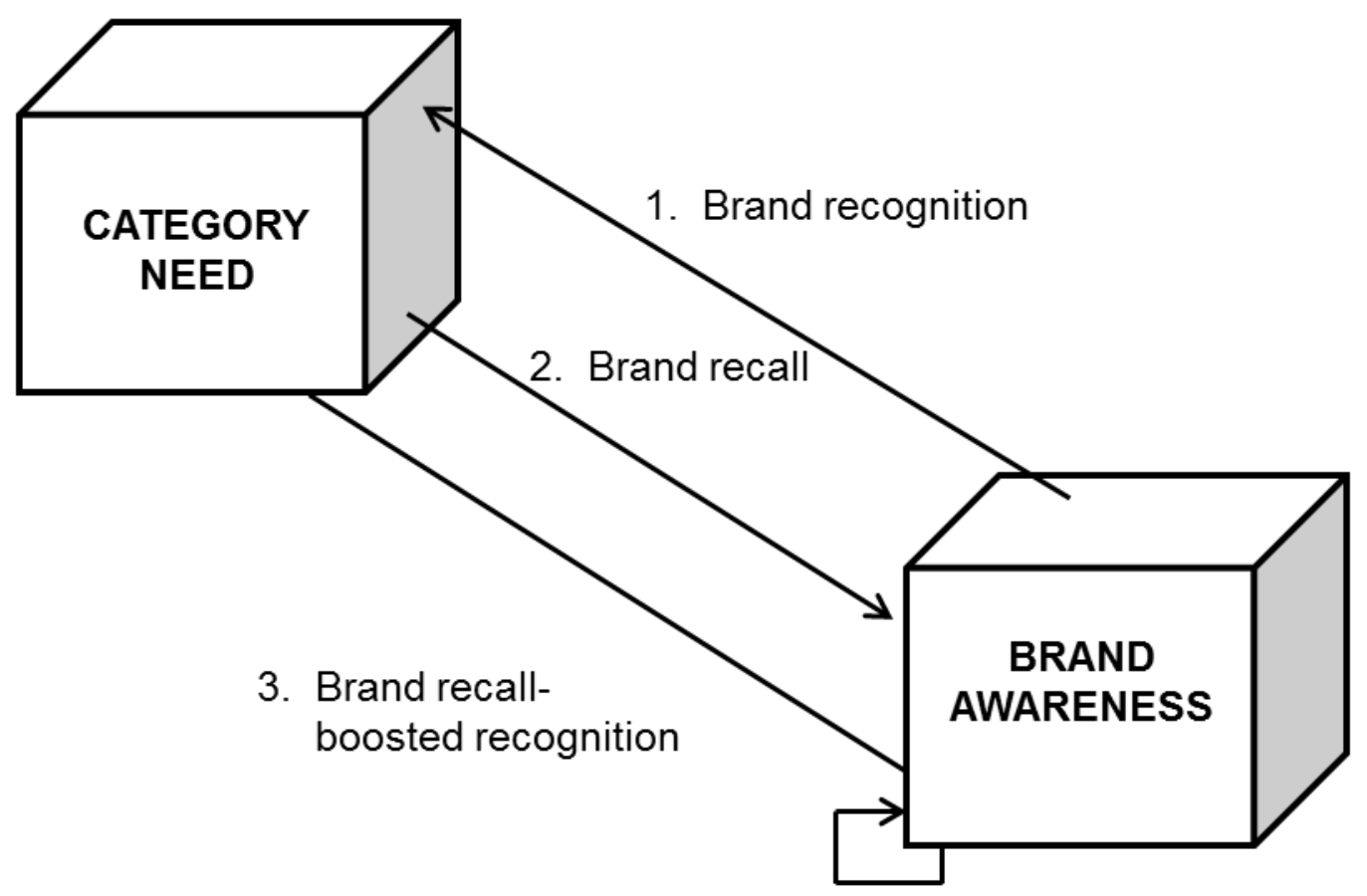


Figure 3: The main components of brand attitude. The typical choice rule (component 4 , not shown in this diagram) is simple summation of components 2 and 3 - though other choice rules are also possible.

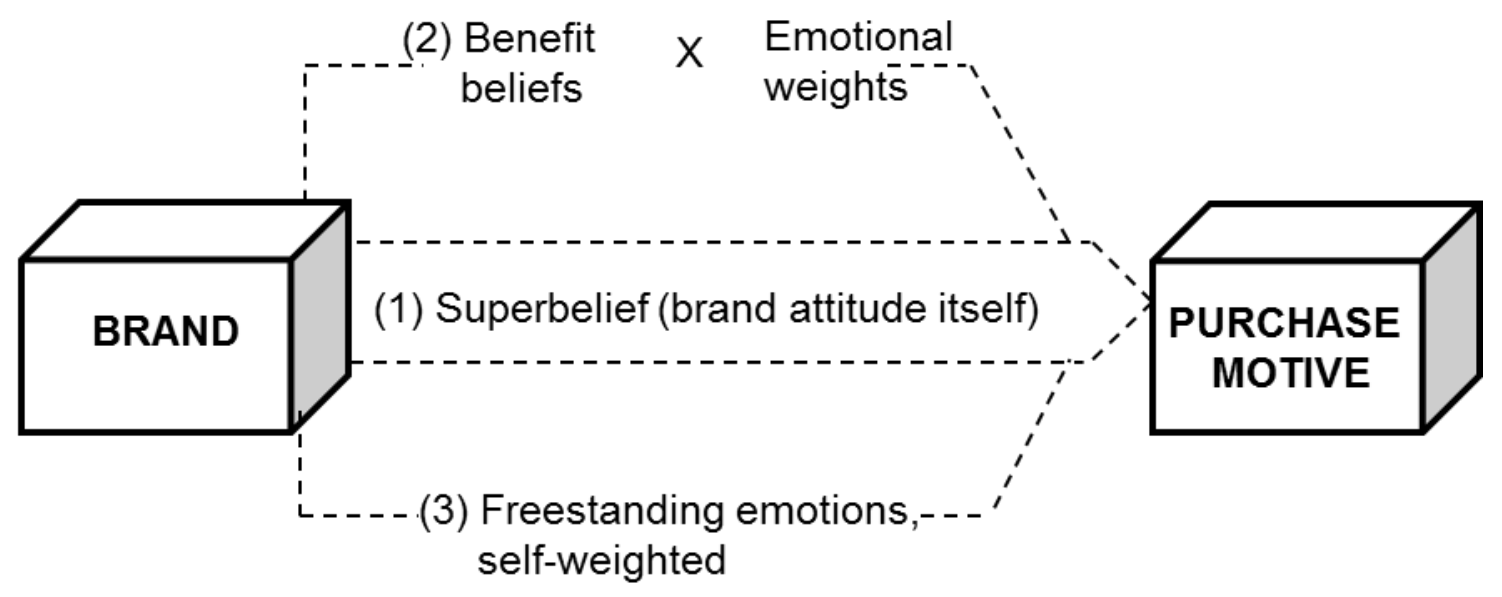


Table 1: Brand awareness defined and measured

BRAND AWARENESS: Buyer's ability to identify (recognize or recall) the brand, within the product or service category, in sufficient detail to make a purchase.

Three types (majority type is derivable from qualitative, one-on-one "walk and talk through your last purchase" interviews):

1. Brand Recognition: Buyer's ability to recognize the brand name when heard, or the stylized name, pack or logo when seen. (Example of measure: SHOW BRAND LOGOS OF POLO SHIRT MANUFACTURERS, ONE AT A TIME. "Have you seen this brand symbol before? $\square$ Yes $\square$ No $\square$ Not sure.")

2. Category-Cued Brand-Name Recall: Buyer's ability to recall the brand name prior to purchase, accurately enough to look for it or order it - when given the category cue. (Example of measure: "When you think of new smartphones, which brands come immediately to mind? RECORD ANSWERS IN ORDER: ." FOR EACH OF THE BRANDS RECALLED, ASK: "For the [e.g.] Samsung smartphone, which model, if any, did you have in mind? $\square$ No particular model $\square$ Model description .)

3. Brand Recall-Boosted Recognition: Buyer's ability to cued-recall the brand, as in \#2, followed by ability to auditorially or visually recognize it, as in \#1. (Example of measure, abbreviated: "Which brands of toothpaste come first to mind? ." THEN SHOW PAGE OF COLOR PACKS OF TOOTHPAST'E, INCLUDING THE CLIENT'S BRAND, AND ASK: "Which of these have you definitely seen before and would be able to find easily in the store? CHECK POSITIVE REPLIES ONLY: $\square$ Optic White $\square$ Total $\square$ Aqua-Fresh $\square$ Sensodyne $\square$ Other." Respondent gets a "yes" on brand recall-boosted recognition only if the brand was recalled and recognized.) 
Table 2: Brand attitude defined and measured

BRAND ATTITUDE: Buyer's evaluation of the brand with respect to its expected capacity to deliver on a currently relevant buying motive.

Informational Buying Motives: Product-focused, problem-solving, therefore negatively reinforce purchase of the brand.

1. Problem removal (anger or pain $\rightarrow$ calm)

2. Problem avoidance (fear $\rightarrow$ relief)

3. Mixed approach-avoidance (guilt $\rightarrow$ resolution)

4. Incomplete satisfaction (disappointment $\rightarrow$ satisfaction)

5. Normal depletion (mild anxiety that supply will run out $\rightarrow$ reassurance)

Transformational Buying Motives: User-focused, experience-enhancing, therefore positively reinforce purchase of the brand.

6 . Sensory gratification (neutral $\rightarrow$ elated)

7. Intellectual stimulation (neutral $\rightarrow$ mentally stimulated)

8. Power (neutral or mild lack of confidence $\rightarrow$ high self-efficacy, heightened sense of control)

9. Pride (neutral $\rightarrow$ sense of belonging to a valued reference group)

10.Social approval (neutral or somewhat negative social-self image $\rightarrow$ flattered)

Best measure of overall brand attitude:

Attitude level

My single preferred brand

One of my preferred brands

An acceptable brand if "on special"

Would not buy this brand under any circumstance

Really don't know enough about this brand to rate it
Suggested scoring

$+5$

$+3$

$+1$

$-3$

0 